\title{
Paralysis and severe disability requiring intensive care in Neolithic Asia
}

\author{
Marc F. OXENHAM ${ }^{1 *}$, Lorna Tilley ${ }^{1}$, Hirofumi MATSUMURA ${ }^{2}$, Lan Cuong NGUYeN $^{3}$, Kim Thuy NGUYen ${ }^{3}$, \\ Kim Dung NGUYEN ${ }^{3}$, Kate DOMETT ${ }^{4}$, Damien HUFFER ${ }^{1}$ \\ ${ }^{1}$ School of Archaeology \& Anthropology, Australian National University, Canberra, ACT 0200, Australia \\ ${ }^{2}$ Department of Anatomy, Sapporo Medical University, Sapporo 060-8556, Japan \\ ${ }^{3}$ Institute of Archaeology, Hanoi, Vietnam \\ ${ }^{4}$ School of Veterinary and Biomedical Science, James Cook University, Townsville, QLD 4811, Australia
}

Received 14 November 2008; accepted 14 January 2009

\begin{abstract}
This communication documents one of the earliest verifiable cases of human paralysis associated with severe spinal pathology. A series of skeletal abnormalities is described for a young adult male (M9) from a Southeast Asian Neolithic community. Differential diagnosis suggests that M9 suffered from a severely disabling congenital fusion of the spine (Klippel-Feil Syndrome, Type III), resulting in child-onset lower body paralysis at a minimum (maximally quadriplegia). M9 experienced severe, most probably total, incapacitation for at least a decade prior to death. In the prehistoric context, this individual's condition would have rendered him completely dependent on others for survival.
\end{abstract}

Key words: quadriparesis, Klippel-Feil, juvenile-onset

\section{Introduction}

While a number of studies in palaeopathology have inferred disabling complications as a consequence of disease and trauma in prehistory (Trinkaus, 1983; Dickel and Doran, 1989; Luna et al., 2008), until now only an individual from early historic period New Mexico (Hawkey, 1998) and one case from late Jomon period ( 3000-4000 years BP) Hokkaido, Japan (Suzuki et al., 1984) have provided unequivocal evidence of extreme and long-term physical impairment in the past. Lack of archaeological evidence for severe disability, reducing our ability to study human behaviour in these circumstances, may reflect: (i) the limited number of diseases that manifest in bone; (ii) death of prehistoric individuals with severe pathologies prior to a skeletal manifestation; or (iii) the poorer preservational potential of pathologically altered skeletal tissues.

In this paper we document the case of MB07H1M09 (M9), an adult male excavated from a Neolithic cemetery ( $\geq 3500$ years BP) in Northern Vietnam, who minimally suffered lower limb paralysis, and maximally quadriplegia, acquired as a young child. M9 represents one of the earliest known demonstrable instances of survival with a disability so severe as to be inconsistent with life without the longterm intervention of a dedicated caregiver(s).

\footnotetext{
* Correspondence to: Marc Oxenham, College of Arts and Social Sciences, Australian National University, Canberra, ACT 0200, Australia.

E-mail: marc.oxenham@anu.edu.au

Published online 10 April 2009

in J-STAGE (www.jstage.jst.go.jp) DOI: 10.1537/ase.081114
}

\section{Biocultural Context}

The site of Man Bac, located in Bach Lien Village, Yen Thanh Commune, Yen Mo District $\left(20^{\circ} 08^{\prime} 00^{\prime \prime} \mathrm{N}\right.$, $109^{\circ} 59^{\prime} 017^{\prime \prime}$ E), between 1999 and 2007 furnished 95 excavated burials in a generally very good state of preservation. The burials are dated between 1524 and 1867 BC (Oxenham et al., 2008); temporally and material culturally belonging to a series of late Neolithic sites (Phung Nguyen Culture) bordering the current Red River delta. An agricultural subsistence base, supplemented with riverine, marine, and terrestrial fauna, is implied for Man Bac; while craft specialization extended to ceramic, jade, and other lithics, as well as shell artefact production (Oxenham et al., 2008). There is evidence for regional trade that may have extended as far as Shang Dynasty China (Higham, 1996). With the exception of 12 poorly preserved burials from Lung Hoa, Man Bac is the only north Vietnamese skeletal assemblage providing a window on the biology and health of people during the missing millennia between the early Neolithic and developed Bronze Age in the region.

\section{Case Description}

M9 was one of only three flexed interments (the remainder being supine/extended and free of serious pathology), but otherwise received a similar mortuary treatment to other adults; his burial position may reflect postural constraints during life. Figure 1 and Figure 2 summarize the preservation of M9; post-mortem loss of the lower thoracic region, including most ribs, majority of lumbar vertebrae and lower appendicular joints makes a definitive diagnosis problematic. Although assessment of sex and age-at-death in skeletal remains displaying evidence of severe long-term 


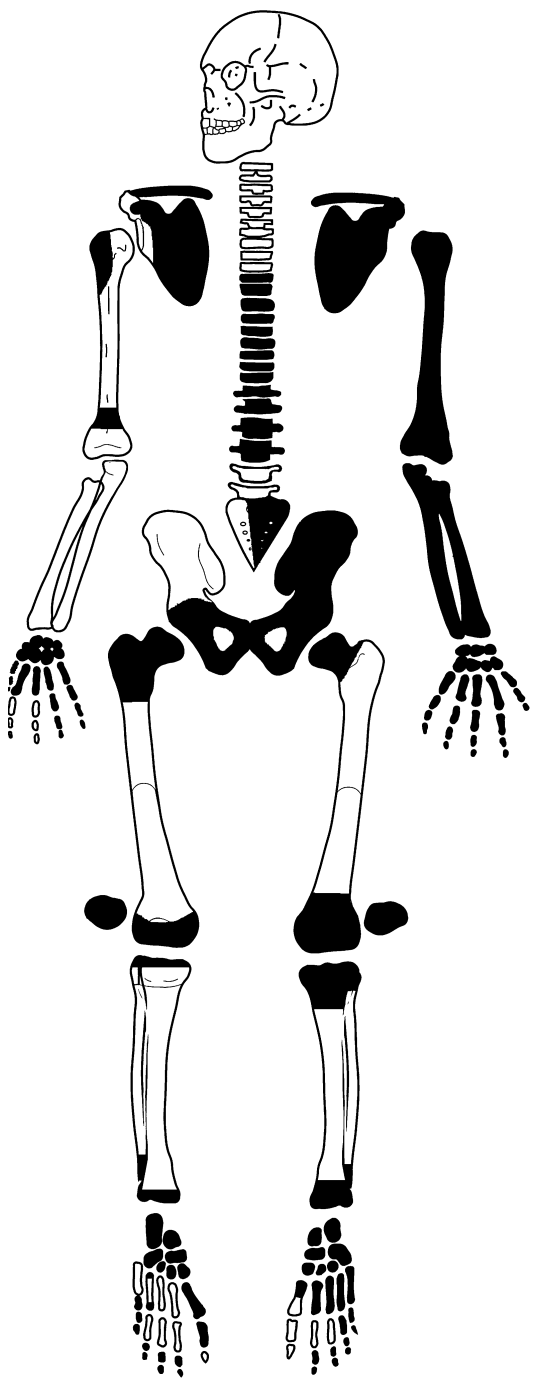

Figure 1. Schematic summarizing the skeletal preservation (black represents missing portions) of MB07H1M09.

pathology is always problematic, the expression of cranial secondary sexual characteristics (nuchal, mastoid and supraorbital size and morphology particularly; as well as frontal bone slope and lack of bossing) is consistent with a male. The sex assessment of male is further supported through the use of Walrath et al.'s method for cranial sex estimation (Walrath et al., 2004). Significant (>30\%) ectoand endocranial suture synostosis and intra-sample comparative molar wear, in addition to full fusion of all preserved epiphyses, suggests age-at-death in the third decade. Pathological cranial and dental conditions include bilateral remodelled cribra orbitalia, slight to moderate calculus deposits on all preserved teeth, and presence of enamel hypoplasia on $\mathrm{LC} \mathrm{LC}^{1}, \mathrm{RI}^{1}, \mathrm{RI}^{2}, \mathrm{LP}_{3}$, and $\mathrm{LC}_{1}$. No evidence for antemortem tooth loss (including tooth ablation), caries, abscessing, or periodontal disease was seen. The mandibular condyles display osteoarthritis (OA) and are strongly asymmetrical, but there is no evidence for bilateral asymmetry in tooth wear.
Preserved vertebrae were ankylosed (includes centra, zygapophyses and laminae) from the first cervical (C1) to third thoracic (T3). While these presented as a continuous block of vertebrae in situ (Figure 3a), fragmentation occurred during lifting. Figure $3 \mathrm{~b}$ shows constriction at the intervertebral junctions of $\mathrm{C} 2 / 3$ and $\mathrm{C} 3 / 4$ (a feature seen throughout the in situ vertebral column prior to removal). Figure $3 c$ illustrates complete fusion at the interarticular processes and adjacent laminae of $\mathrm{C} 5-\mathrm{C} 7$ as well as extremely small, often completely obliterated, and somewhat oval in shape intervertebral foramina (again, this was seen throughout the in situ vertebral column). Additional complications included occipitalization and atlantoaxial rotatory $\left(>30^{\circ}\right)$ fixation (subluxation) with the anterior aspect of the dens separated from the corresponding $\mathrm{C} 2$ facet by $8 \mathrm{~mm}$; resultant $\mathrm{C} 1 / \mathrm{C} 2$ stenosis may have been mitigated by the apparent aplasia of $\mathrm{C} 1$ posterior neural arch (Figure 4). Stenosis is indicated by the relatively small anteroposterior neural canal diameters of C2 $(13.1 \mathrm{~mm})$ and C3 $(11.7 \mathrm{~mm})$. It was not possible to assess the presence or absence of lower vertebral or sacral spina bifida due to poor preservation of this region. A fragmentary, very gracile, right os coxae was ankylosed at the auricular area.

All preserved major long bones have significantly reduced diaphyseal diameters relative to other adult Man Bac individuals (Table 1). Only the right humerus, radius, and ulna have preserved articular portions. The humeral olecranon fossa and trochlea is free of OA, while the head displays marked anteromedial osteophytosis and porosity. There is a sharp, prominent deltoid crest ( $\sim 40 \mathrm{~mm}$ long, raised $\sim 5 \mathrm{~mm}$ ) and a very deep intertubercular groove extending to the deltoid insertion. The radial proximal ulnar facet and capitular surface display OA, while distally OA free, and there is minimal development of the biceps tuberosity. The right ulna has a roughened triceps insertion, but no ossification of this tendon, and proximal, but not distal, OA.

Both femoral diaphyses are significantly compressed anteroposteriorly, with the left (better preserved) displaying marked flaring superiorly, initiating just inferior to the lesser trochanter. The lesser trochanter of the left femur (not preserved in the right) manifests unusually as a sharp medial ridge (21.6 $\mathrm{mm}$ superoinferior length, projecting $\sim 9.0 \mathrm{~mm}$ ). Linea aspera in both femora manifests as very slight and sharpish ridges. Both tibiae are also very gracile with minimal expression of muscle insertions. The fibulae appear exceptionally fragile (minimum diameter of the neck in the right is only $2.9 \mathrm{~mm}$ ), with the better preserved right diaphysis showing marked proximal metaphyseal flaring.

Proximal and middle hand phalanges are superoinferiorly compressed, with the proximal phalanges manifesting flaring proximal articular regions and mediolaterally compressed distal regions with the addition of slight anterior palmar curvature. OA was not seen on assessable right or left foot elements, although the proximal phalanges of the second, third, and fourth rays of the right foot have relatively narrow diaphyses with flaring and slightly cupped metatarsophalangeal facets. 


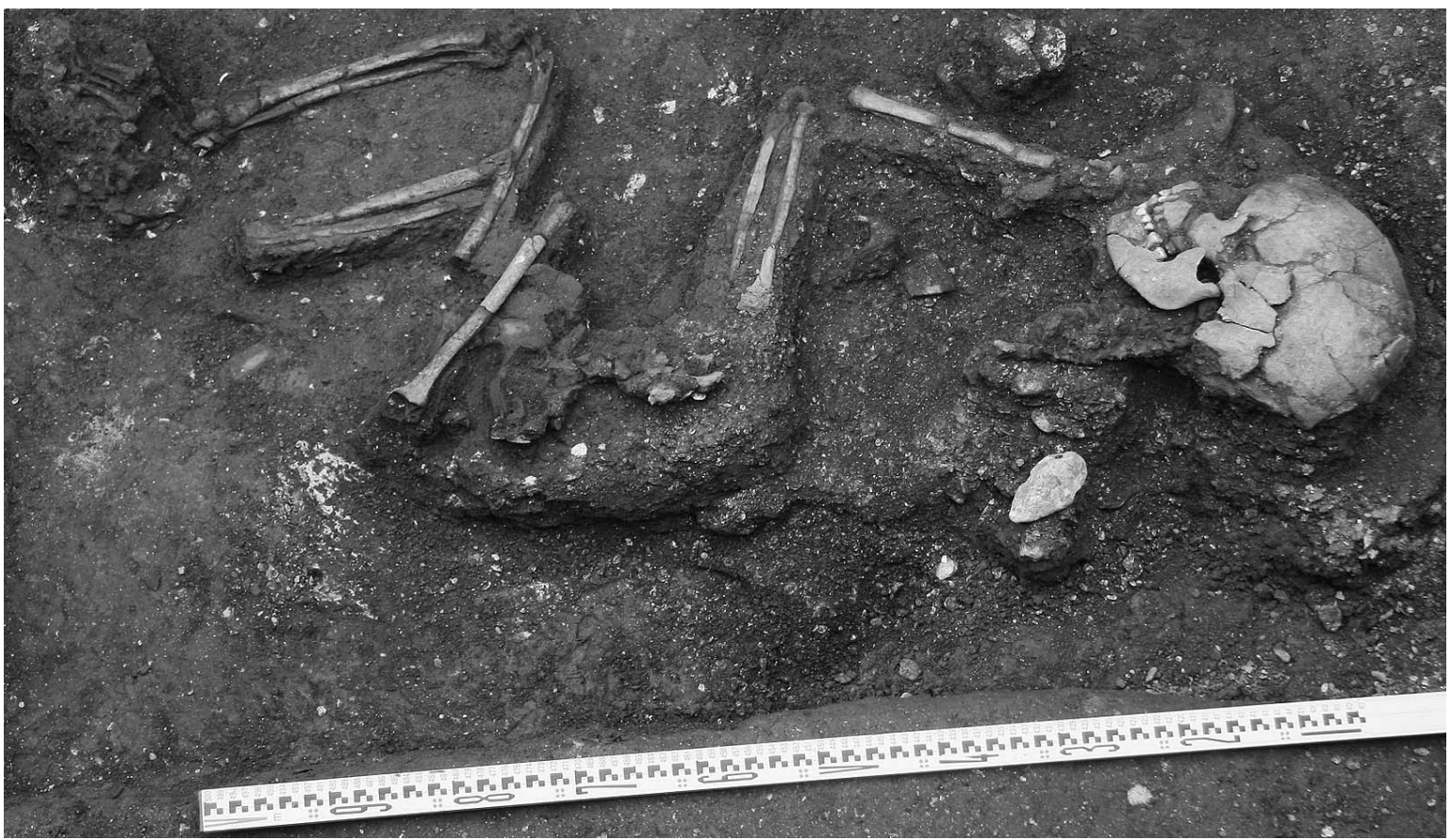

Figure 2. Photograph of MB07H1M09 in situ prior to removal. Note extreme gracility of limbs.

\section{Differential Diagnosis}

In developing a differential diagnosis, the exceptionally slender nature of the limbs, particularly M9's legs, is consistent with clinical descriptions of adult patients with spinal cord injury (SCI) occurring as a juvenile (Giangregorio and McCartney, 2007). SCI occurring post-adolescence typically leads to a significant loss of bone endosteally, resulting in an enlarged medullary cavity and thinner cortical walls, but the maintenance of diaphyseal diameter (Modlesky et al., 2005). The post-mortem loss of the epiphyseal areas of the lower limbs may be explained by much greater bone loss in this region relative to the diaphysis in the unloaded limbs of SCI individuals (Eser et al., 2004). The gracility of the preserved upper limbs also suggests some level of unloading before adulthood (hand and foot bone diaphyseal atrophy is also relevant in this regard), given that bone loss is restricted to unloaded limbs and is not a systemic condition in SCI individuals (Zehnder et al., 2004). However, the greater robustness of these limbs relative to the lower limbs, as well as evidence for OA and deltoid muscle use, indicates functional quadriparesis with intermittent or limited upper limb function. M9 also suffered from a permanent and severe torticollis and right rotation of the head, which may have led to restricted right side temporomandibular function.

Given that M9 suffered from quadriplegia or quadriparesis from some time prior to adolescence, there is a question regarding the underlying cause(s) of this seriously debilitating condition and whether neurological impairment preceded or was a consequence of the ankylosed spine. While spinal ankylosis, as well as sacroiliac fusion, has been observed to develop in paralysed individuals (Park et al., 1993), the extent and nature of the fused vertebral column in this case is not consistent with such a scenario. If spinal ankylosis preceded or was coincidental with neurological impairment, several juvenile-onset conditions need to be considered: Klippel-Feil syndrome (KFS), fibrodysplasia ossificans progressiva (FOP) and juvenile idiopathic arthritis (JIA).

Two forms of juvenile-onset arthritis that can cause severe vertebral ankylosis, juvenile rheumatoid arthritis (JRA) and juvenile-onset ankylosing spondylitis (JOAS), are now classified under the ILAR system as subcategories of JIA (Tse and Laxer, 2003; Duffy et al., 2005). However, from a palaeopathological standpoint, there is value in differentiating between JOAS and JRA as these conditions have quite distinct skeletal signatures. In adult RA vertebral lesions can include occipitalization, erosion of cervical apophyseal joints, and, rarely, sacroiliac lesions, while in JRA vertebral ankylosis can occur at the destroyed apophyseal joints, leaving the centra unaffected (Hadley, 1976). With JOAS occipitalization is rare, while sacroiliac lesions and widespread enthesitis are characteristic with the potential for ankylosis of the lumbar then thoracic vertebrae (Hadley, 1976). The morphology of early vertebral ankylosis, in childhood, may mimic congenital fusion or non-segmentation (Hadley, 1976). In JRA, appendicular joint disease is much more common in the upper extremities (particularly wrist, interphalangeal and metacarpophalangeal), while tarsal involvement and enthesitis is very common with JOAS (BurgosVargas and Vazquez-Mellado, 1995). While poor preservation of appendicular epiphyseal areas in M9 may be masking erosive lesions and ankylosed joints, the lack of such lesions in the preserved joints tends to exclude JIA in general, and JOAS and JRA specifically, from further consideration.

FOP is a rare, 1 in 1.6 million, condition characterized by vertebral fusion as well as extensive and ultimately severely 
(a)

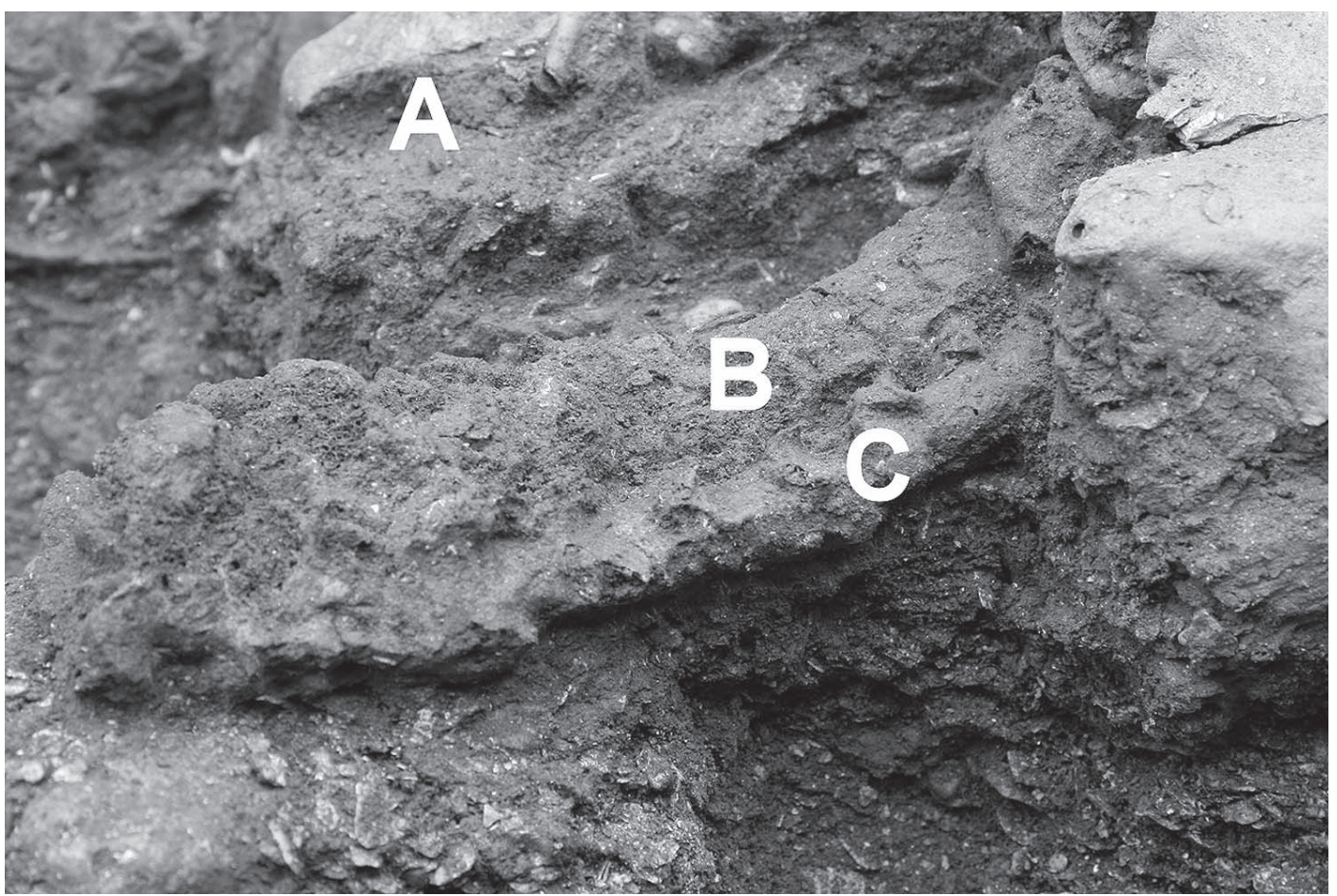

(b)

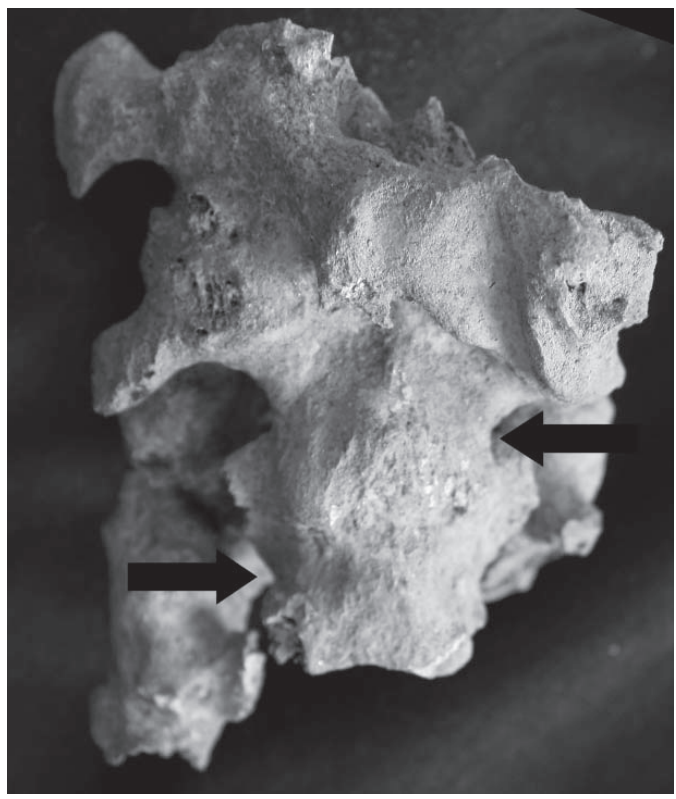

(c)

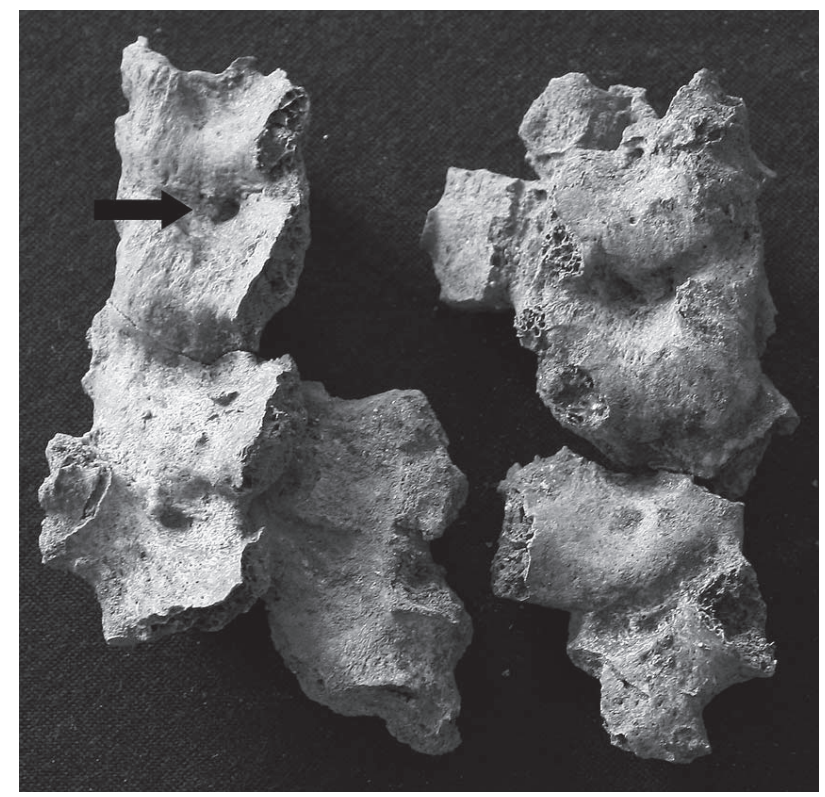

Figure 3. (a) Left oblique view of the fused vertebrae (C1-T1 in situ). The posterior body of the mandible (damaged post-mortem) has been removed (A) to facilitate examination of the superior cervical vertebrae. Note the flattened, fused vertebral bodies (B) and continuous fusion along the transverse processes (C). (b) Anterior aspect of ankylosed C1 to superior aspect of C4. Arrows indicate areas of intervertebral junction constriction (characteristic of congenital vertebral fusion). (c) Posterior aspect of C5-C7. The vertebral bodies (centra) disintegrated upon removal. Complete fusion at zygapophyseal joints and laminae, as well as small oval intervertebral foramina (see black arrow) is indicative of congenital fusion.

disabling heterotopic ossification and appendicular joint ankylosis (Kaplan et al., 2005). While both FOP and KFS are characterized by ankylosis of the cervical spine, and as few as two contiguous vertebrae can be involved in both conditions, vertebral centra in FOP are typically narrow with enlarged pedicles and spinous processes and occipitalization does not occur (Schaffer et al., 2005). Moreover, the lack of heterotopic ossification, appendicular joint ankylosis and 


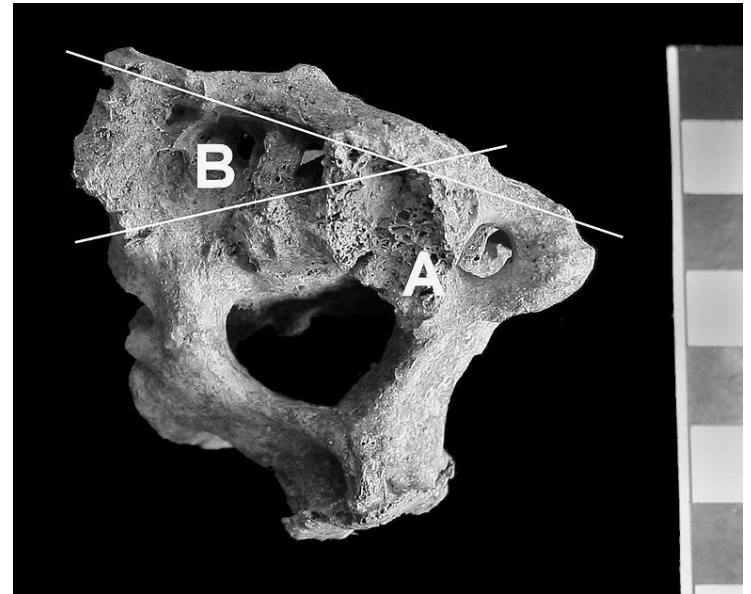

Figure 4. $\mathrm{C} 1$ and $\mathrm{C} 2$ illustrating occipitalization (the roughened bone at point $\mathrm{A}$ is the broken right occipital condyle fused to the superior $\mathrm{C} 1$ condylar facet) and rotatory fixation. Note ossified connective tissue (point B) between the anterior dens and $\mathrm{C} 1$ dens facet. $\mathrm{C} 1$ neural arch is missing either post-mortem or due to arch aplasia. The two lines help to identify the degree and direction of $\mathrm{C} 1$ rotation on $\mathrm{C} 2$.

congenital malformation of the great toes in this case (Kaplan et al., 2005) excludes FOP from further consideration.

KFS is a segmentation disorder characterized by the congenital fusion of two or more cervical vertebrae with an estimated prevalence of 1 in 40,000-42,000 (Samartzis et al., 2006). Two important features of KFS vertebrae are: (i) an apparent restriction at the interspace of the fused vertebral bodies (Hadley, 1976, Fig. III: 12, p. 81), also described as 'wasp-waist sign' (Nguyen and Tyrrel, 1993); and (ii) relatively small, round or oval intervertebral foramina (Hadley, 1976). M9 meets the criteria for KFS Type III (multiple continuous fused cervical vertebrae), which is associated with a relatively high risk of radiculopathic and myelopathic symptoms (Samartzis et al., 2006). The association of Type III and occipitalization is also correlated with a much greater risk of superior ondontoid migration (SOM) and concomitant neural compression (Samartzis et al., 2007). While postmortem damage to the occipital region makes determination of SOM difficult, some level of stenosis is apparent at $\mathrm{C} 2$ and $\mathrm{C} 3$, although $\mathrm{C} 1$ neural arch aplasia would have relieved compression potentially resulting from $\mathrm{C} 1 / \mathrm{C} 2$ subluxation.
Serious neurological impairment in both children and adults has been recorded in association with KFS, e.g. intermittent quadriparesis (Ritterbusch et al., 1991). Further, there is an increased risk of serious SCI subsequent to trauma in KFS individuals (Strax and Baran, 1975).

KFS in its milder Type I and II forms has been documented in a number of archaeological sites globally from as early as 5000 BC through to medieval times: Japan (Fukushima, 1988); Portugal (Fernandes and Costa, 2007; Silva and Ferreira, 2008); Hungary (Pany and Teschler-Nicola, 2007); Greece (Papathanasiou, 2005); Central and South America (Urunuela and Alvarez, 1994); North America (see Barnes, 1994 for an extensive review). Apart from Man Bac burial 9 the only other extreme form of KFS known to the authors is that of a pre-Hispanic ( 1450-1500 AD) female aged 30-40 years from Cholula, Puebla, Mexico with vertebral fusion from C2 to T1 but not appearing to suffer from any form of paralysis (Urunuela and Alvarez, 1994).

\section{Conclusions}

The description of and differential diagnosis considered for this individual suggests he suffered from a congenital segmentation disorder as a child, leading to fusion of his cervical spine and concomitant or subsequent severe neurological impairment (likely quadriparesis or quadriplegia). The functional impact of M9's condition was, at a minimum, to render him completely immobile below the waist and to radically limit upper body mobility. Additional posture-related complications include a fixed right rotation of his head with severe torticollis and potentially restricted masticatory function. In this Late Neolithic culture this would have left M9 completely dependent on others for every aspect of daily living. There is a well-documented range of systemic complications associated with immobility (Olson et al., 1967), and this has implications for the amount and type of care required by M9. M9 lived into his third decade, and his survival for ten years or more following onset of immobility/paralysis would have required constant care and episodes of intensive nursing. The implications of his experience for understanding social practice in this Neolithic community will be explored in detail in a future communication.

Table 1. M9 compared to normal Man Bac adult range of mid-diaphyseal diameters (humerus, radius, femur in mm)

\begin{tabular}{|c|c|c|c|c|c|c|c|c|c|c|c|c|}
\hline & \multicolumn{4}{|c|}{ Humerus } & \multicolumn{4}{|c|}{ Radius } & \multicolumn{4}{|c|}{ Femur } \\
\hline & $\min$ & $\max$ & mean & $\mathrm{M}^{2}$ & $\min$ & $\max$ & mean & M9 & $\min$ & $\max$ & mean & M9 \\
\hline $\mathrm{N}^{1}$ & $8(11)$ & $8(11)$ & & & $8(12)$ & $8(12)$ & & & $9(13)$ & $9(13)$ & & \\
\hline $\mathrm{AP}^{3}$ & 19.6 & 26.0 & 21.7 & 15.0 & 9.7 & 14.2 & 11.3 & 7.5 & 23.8 & 35.6 & 27.3 & $14.5 / 13.8^{4}$ \\
\hline $\mathrm{ML}^{3}$ & 14.2 & 19.1 & 15.8 & 10.6 & 11.7 & 17.4 & 14.1 & 12.3 & 20.1 & 29.0 & 25.7 & $15.7 / 11.9$ \\
\hline SD & 2.0 & 1.5 & & & 1.6 & 2.0 & & & 3.4 & 2.8 & & \\
\hline
\end{tabular}

${ }^{1}$ individuals (elements)

${ }^{2}$ MB07H1M09

${ }^{3}$ AP anterioposterior diameter; ML mediolateral diameter; Note that for the humerus maximum diameter was taken in lieu of AP and minimum diameter taken in lieu of ML

${ }^{4}$ left/right dimensions 


\section{Acknowledgments}

We thank F. Kaplan, F. Shen and P. Smith for important discussions concerning the differential diagnosis. M.O. was funded by an Australian Research Council Discovery Grant and H.M. by a Toyota Foundation (No. D06-R-0035) and the Japan Society of the Promotion of Science (No. 20370096).

\section{References}

Barnes E. (1994) Developmental Defects of the Axial Skeleton in Palaeopathology. University Press of Colorado, Denver, CO.

Burgos-Vargas R. and Vazquez-Mellado J. (1995) The early clinical recognition of juvenile-onset ankylosing spondylitis and its differentiation from juvenile rheumatoid arthritis. Arthritis \& Rheumatism, 38: 835-844.

Dickel D.N. and Doran G.H. (1989) Severe neural tube defect syndrome from the Early Archaic of Florida. American Journal of Physical Anthropology, 80: 325-334.

Duffy C.M., Colbert R.A., Laxer R.M., Schanberg L.E., and Bowyer S.L. (2005) Nomenclature and classification in chronic childhood arthritis: time for a change? Arthritis \& Rheumatism, 52: 382-385.

Eser P., Frotzler A., Zehnder Y., Wick L., Knecht H., Denoth J., and Schiessl H. (2004) Relationship between the duration of paralysis and bone structure: a pQCT study of spinal cord injured individuals. Bone, 34: 869-880.

Fernandes T. and Costa C. (2007) Klippel-Feil syndrome with other associated anomalies in a medieval Portuguese skeleton (13th-15th century). Journal of Anatomy, 211: 681-685.

Fukushima K. (1988) On the lesions of bones of Yayoi people in southwest Japan. Fukuoka Acta Medica, 79: 227-248.

Giangregorio L.M. and McCartney N. (2007) Reduced loading due to spinal-cord injury at birth results in 'slender' bones: a case study. Osteoporosis International, 18: 111-120.

Hadley L.A. (1976) Anatomico-Roentgenographic Studies of the Spine. C.C. Thomas, Springfield, IL.

Hawkey D.E. (1998) Disability, compassion and the skeletal record: using musculoskeletal stress markers (MSM) to construct an osteobiography from early New Mexico. International Journal of Osteoarchaeology, 8: 326-340.

Higham C.F.W. (1996) The Bronze Age of Southeast Asia. Cambridge University Press, Cambridge.

Kaplan F.S., Glaser D.L., Shore E.M., Deirmengian G.K., Gupta R., Delai P., Morhart R., Smith R., Le Merrer M., Rogers J.G., Connor J.M., and Kitterman J.A. (2005) The phenotype of Fibrodysplasia Ossificans Progressive. Clinical Reviews in Bone and Mineral Metabolism, 3: 183-188.

Luna L.H., Aranda C.M., Bosio L.A., and Beron M.A. (2008) A case of multiple metastasis in Late Holocene hunter-gatherers from the Argentine Pampean region. International Journal of Osteoarchaeology, 18: 492-506.

Modlesky C.M., Slade J.M., Bickel C.S., Meyer R.A., and Dudley G.A. (2005) Deteriorated geometric structure and strength of the midfemur in men with complete spinal cord injury. Bone, 36: 331-339.

Nguyen V.D. and Tyrrel R. (1993) Klippel-Feil syndrome: patterns of bony fusion and wasp-waist sign. Skeletal Radiology, 22: $519-523$
Olson E., Johnson B.J., Thompson L.F., McCarthy J.A., Edmonds R.E., Schroeder L.M., and Wade M. (1967) The hazards of immobility. American Journal of Nursing, 67: 780-797.

Oxenham M., Matsumura H., Domett K., Nguyen K.T., Nguyen K.D., Nguyen L.C., Huffer D., and Muller S. (2008) Childhood in late Neolithic Vietnam: biomortuary insights into an ambiguous life stage. In: Bacvarov K. (ed.), Babies Reborn: Infant/Child Burials in Pre-and Protohistory. BAR International Series 1832, pp. 123-136.

Pany D. and Teschler-Nicola M. (2007) Klippel-Feil Syndrome in an Early Hungarian Period juvenile skeleton from Austria. International Journal of Osteoarchaeology, 17: 403-415.

Papathanasiou A. (2005) Health status of the Neolithic population of Alepotrypa Cave, Greece. American Journal of Physical Anthropology, 126: 377-390.

Park Y., Huang G., Taylor J., Marcelis S., Kramer J., Pathria M.N., Clopton P.C., and Resnick D. (1993) Patterns of vertebral ossification and pelvic abnormalities in paralysis: a study of 200 patients. Radiology, 188: 561-565.

Ritterbusch J., McGinty L.D., Spar J., and Orrison W.W. (1991) Magnetic resonance imaging for stenosis and subluxation in Klippel-Feil Syndrome. Spine, 16: S539-S541.

Samartzis D., Herman J., Lubicky J.P., and Shen F.H. (2006) Classification of congenitally fused cervical patterns in KlippelFeil patients: epidemiology and role in the development of cervical spine-related symptoms. Spine, 31: E798-E804.

Samartzis D., Kalluri P., Herman J., Lubicky J.P., and Shen F.H. (2007) Superior odontoid migration in the Klippel-Feil patient. European Spine Journal, 16: 1489-1497.

Schaffer A.A., Kaplan F.S., Tracy M.R., O’Brien M.L., Dormans J.P., Shore E.M., Harland R.M., and Kusumi K. (2005) Developmental anomalies of the cervical spine in patients with Fibrodysplasia Ossificans Progressive are distinctly different from those in patients with Klippel-Feil Syndrome. Spine, 30: 1379-1385.

Silva A.M. and Ferreira M.T. (2008) C2-C3 block vertebrae in a late Neolithic/Chalcolithic child exhumed from a Portuguese collective grave. HOMO, 59: 41-46.

Strax T.E. and Baran E. (1975) Traumatic quadriplegia associated with Klippel-Feil syndrome: discussion and case reports. Archives of Physical Medicine and Rehabilitation, 56: 363 365.

Suzuki T., Mineyama I., and Mitsuhashi K. (1984) Paleopathological study of an adult skeleton of Jomon period from Irie shell mound, Hokkaido. Journal of the Anthropological Society of Nippon, 92: 87-104.

Trinkaus E. (1983) The Shanidar Neanderthals. Academic Press, New York.

Tse S.M.L. and Laxer R.M. (2003) Juvenile spondyloarthropathy. Current Opinion in Rheumatology, 15: 374-379.

Urunuela G. and Alvarez R. (1994) A report of Klippel-Feil Syndrome in Prehispanic remains from Cholula, Puebla, Mexico. Journal of Paleopathology, 6: 63-67.

Walrath D.E., Turner P., and Bruzek J. (2004). Reliability test of the visual assessment of cranial traits for sex determination. American Journal of Physical Anthropology, 125: 132-137.

Zehnder Y., Luthi M., Michel D., Knecht H., Perrelet R., Neto I., Kraenzlin M., Zach G., and Lippuner K. (2004) Long term changes in bone metabolism, bone mineral density, quantitative ultrasound parameters, and fracture incidence after spinal cord injury: a cross-sectional observational study in 100 paraplegic men. Osteoporosis International, 15: 180-189. 